\title{
EL FANZINE Y LA COMUNICACIÓN DEL RIESGO: UNA PROPUESTA PARA EL VALLE DEL CAUCA, COLOMBIA
}

Javier Thomas ${ }^{1 *}$, Julio Rubio ${ }^{1,2}$ e Isabel Muñoz ${ }^{1,3}$

\section{RESUMEN}

Uno de los aspectos que no ha sido significativamente valorado en el proceso de gestión del riesgo es el de las estrategias comunicativas. Este trabajo recoge la experiencia de un proyecto de investigación en el que se realizaron talleres pedagógicos que permitieron, de una parte, recrear hechos y experiencias particulares vividas por las personas en situaciones de riesgo, y de otra, resignificarlas para producir fanzines, como piezas comunicativas que, con sentido social y construcción colectiva, permiten abordar, contextualmente, aspectos particulares de la gestión social del riesgo. En este caso, en los municipios de Jamundí, Yumbo, Buga, Buenaventura, Sevilla y Ansermanuevo, del Departamento del Valle del Cauca, Colombia, con participación de las autoridades ambientales y las comunidades de base, se hicieron talleres que, sumados a la evaluación de piezas comunicativas institucionales existentes sobre la gestión del riesgo, posibilitaron hacer un balance de concepción y alcances de la comunicación del riesgo, como parte inherente de la política pública en el tema.

\section{PALABRAS CLAVE}

Fanzine, Comunicación del riesgo, Gestión del Riesgo, Valle del Cauca, Colombia

FANZINE AND RISK COMMUNICATION: A PROPOSAL FOR THE VALLE DEL CAUCA, COLOMBIA

\section{ABSTRACT}

One of the aspects that we consider need to be more valued in the risk management process is that of communication strategies. This work gathers the experience of a research project in which pedagogical workshops were held that, on the one hand, recreate particular facts and experiences lived by people in risk situations, and on the other, re-signify them to produce fanzines: communicative pieces that, with a social sense and collective construction, allow to address, contextually, particular aspects of social risk management. With the participation of environmental authorities and communities from the municipalities of Jamundí, Yumbo, Buga, Buenaventura, Sevilla and Ansermanuevo, in the Department of Valle del Cauca, Colombia, in addition to the evaluation of institutional communications on risk management, workshops made possible to evaluate of conception and scope of risk communication as an inherent part of public policy on the subject.

\section{KEYWORDS}

Fanzine, Risk Communication, Risk Management, Valle del Cauca, Colombia
1. Departamento de Geografía, Universidad del Valle, Colombia.

2. Universidad San Buenaventura Cali, Colombia.

3. Fundación Jardín Botánico de Cali

*Autor de correspondencia: javier.thomas@ correounivalle.edu.co

\section{RECIBIDO}

6 de septiembre de 2017

\section{ACEPTADO}

21 de octubre de 2017

\section{PUBLICADO}

30 de enero de 2018

Formato cita

Recomendada (APA):

Thomas, J., Rubio, J. \&

Muñoz, I. (2018). El Fanzine y la comunicación del riesgo: Una propuesta para el Valle del Cauca, Colombia. REDER, 2(1), pp.53-70.

Todos los artículos publicados en REDER siguen una política de Acceso Abierto y se respaldan en una

Licencia CreativeCommons Atribución-NoComercial 4.0 Internacional.

Revista de Estudios Latinoamericanos sobre Reducción del Riesgo de Desastres (REDER) 


\section{A MODO DE PRESENTACIÓN}

El presente texto da cuenta de una experiencia de investigación situada social y territorialmente en seis municipios del Departamento del Valle del Cauca, Colombia. En cada uno de ellos se realizó un taller pedagógico (seis en total), sobre la comunicación del riesgo; en éstos, con la participación de las autoridades respectivas en el tema ${ }^{1} \mathrm{y}$ de las comunidades, que sumaron entre todos entre $15 \mathrm{y}$ 35 asistentes por taller, tres talleristas, en un promedio de tres horas y media, desarrollaron dos grandes secciones autónomas pero complementarias. En la primera, se recrearon situaciones de riesgo ante sismos e incendios que exigían respuestas inmediatas de los participantes para poner a salvo sus vidas; en éstas, los asistentes tenían los ojos vendados, cuya pretensión era, además de simular la noche o de circunstancias de confinamiento, producir en ellos condiciones de vulnerabilidad que luego serían retomadas en el momento técnico del taller. La segunda sección, centrada en la propuesta comunicativa, se focalizó en el Fanzine, como alternativa comunicativa participativa. Allí los participantes construyeron fanzines con recursos cotidianos (revistas, periódicos, hojas de papel, etc.), que presentaban situaciones de riesgo y su posible gestión, en sus comunidades en particular.

La evaluación de los talleres se realizó de parte del equipo de investigación a partir de una tabla de intensidades definidas para ellos y una matriz que reconoció el nivel de alcance logrado de los principios pedagógicos, ambas explicadas más adelante.

En relación con el contexto geográfico particular en que se desarrolló el proyecto, es importante decir que el Valle del Cauca es un Departamento al Suroccidente de Colombia que, a lo largo del valle geográfico del río cauca, comprende 42 municipios. De entre ellos, se seleccionaron los de Jamundí, Yumbo, Buga, Buenaventura, Sevilla y Ansermanuevo, ya que al estar repartidos en los diversos puntos cardinales y tener distintas categorías administrativas, resultan representativos de la situación departamental.

Los municipios de Jamundí, Yumbo y Buga, a pesar de estar situados en el eje geográfico del valle aluvial de río Cauca, su principal sello, también tienen áreas rurales en zonas de ladera, que definen amenazas y riesgos tanto por eventos inundables como por remoción en masa. El municipio de Buenaventura, en la costa pacífica, presenta una situación particular, no sólo por ser portuario, sino por las condiciones étnicas y ecosistémicas: negritudes y manglares, establecen una riqueza cultural y ambiental importante que es necesario mantener y recuperar, pero que a la vez configuran fuertes tensiones y conflictos con el puerto, definiéndose así complejas vulnerabilidades ante tsunamis, inundaciones fluviales y marinas y procesos de remoción en masa, en una parte de la ciudad, como en su zona montañosa, en los llamados Farallones de Cali, en el flanco occidental de la cordillera occidental. El municipio de Sevilla, sobre la cordillera central, casi completamente montañoso, no sólo tiene la fama de producir un excelente café, sino tener los procesos más fuertes y activos de deslizamientos y flujos de tierra y suelo, de todo el departamento. Por su parte, el de Ansermanuevo, sobre la cordillera occidental, también en su mayoría montañoso, está expuesto a procesos de remoción en masa, pero también en su casco urbano por inundaciones torrenciales que ya han causado tragedias en el pasado. Además todos los municipios, sin excepción alguna, en mayor o menor grado están expuestos a los eventos de mayor afectación e impacto local y regional, los sismos, cuya génesis depende del sistema de fallas Cauca-Romeral, que a modo de tridente atraviesa en sentido noreste-suroeste la región y de la subducción de la placa de Nazca sobre la Americana, que como parte del cinturón de fuego del pacífico, es responsable de la mayoría de los eventos de gran magnitud que se presentan en el territorio colombiano.

\section{LA COMUNICACIÓN DEL RIESGO}

La comunicación del riesgo es un elemento poco desarrollado tanto en la normativa colombiana como en la misma academia, la Ley 1523 de 2012 establece en el artículo 4ㅇ, en el que se refiere a las Definiciones, que el Conocimiento del riesgo, es "el proceso de la gestión del riesgo compuesto por la identificación de escenarios de riesgo, el análisis y evaluación del riesgo, el monitoreo y seguimiento del riesgo y sus componentes y la comunicación para promover una mayor conciencia del mismo que alimenta los procesos de reducción del riesgo y de manejo de desastre". Esta es la alusión más directa sobre el tema que aparece en la ley, y a partir de allí, cabe preguntarnos ¿Qué es una comunicación para

1. Oficinas de gestión del riesgo, de planeación, cuerpos de atención y socorro, y en algunos casos de promotores ambientales. 
promover una mayor conciencia del riesgo, que alimente los procesos de reducción de éste y del manejo de desastre? Y más allá aún ¿Qué es, o sería, una comunicación del riesgo? ¿Qué objetivos y alcances tendría? ¿Cómo se implementaría? ¿A quiénes involucraría?

Por su parte, la OPS y OMS (2017) consideran que "la comunicación de riesgo se refiere al intercambio en tiempo real, de información, recomendaciones y opiniones, entre expertos $y / 0$ funcionarios $y$ personas que se enfrentan a una amenaza (riesgo) para su sobrevivencia, su salud o su bienestar económico o social. El objetivo final de la comunicación de riesgos es que toda persona expuesta a un riesgo sea capaz de tomar decisiones informadas para mitigar los efectos de la amenaza (riesgo), como el brote de una enfermedad, y tomar las medidas y acciones de protección y prevención".

Precisamente este es el enfoque que ha primado en el tema de la comunicación del riesgo; estas dos instituciones, en el marco del Plan Continental de Ampliación e Intensificación de Combate al Aedes aegypti, han dirigido varias experiencias en el continente americano, con base en la metodología COMBI (Comunicación para Impactar en Conductas). Se busca, a través de un proceso conductual, promover acciones que generen cambios en los comportamientos de la población que los exponen a los vectores de riesgo. Los resultados de este proceso muestran fortalezas en la integración de programas y acciones para combatir el dengue en estas regiones, pero no hay evidencias de que la comunicación del riesgo se asuma en doble vía y que permita que las administraciones locales y nacionales, al igual que los organismos internacionales, recojan e incorporen, como parte del saber colectivo e institucional, las concepciones y percepciones que las comunidades tienen del riesgo, así como de sus factores genéticos (OPS, 2011).

No obstante lo representativo de la definición planteada por la OPS y la OMS y de los resultados de las experiencias desarrolladas, tenemos posturas diferentes frente al tema; empezaremos diciendo que Comunicar es diferente de Informar. El informar, se trata de un proceso unidireccional, unilateral, que asume al receptor de un mensaje como sujeto pasivo, cuasi-objeto, que bajo un mecanismo causa-efecto, dispara una reacción en función del mensaje recibido; mientras que el comunicar implica una construcción conjunta de mensajes, en doble vía, en donde las interacciones permanentes entre emisor-receptor, generan constantes intercambios de sus roles y una reconfiguración continua de los mensajes.

Esto se hace patente en los diversos documentos institucionales sobre el tema existentes en Colombia, pero en especial, en oposición a su carácter, en la Guía Comunitaria para la Gestión del Riesgo de Desastres, elaborada por la Unidad Nacional de Gestión del Riesgo de Desastres (2013a). En ella se aprecia que la comunicación del riesgo se entiende como un proceso unidireccional de "capacitar-informar" a las comunidades locales, entendidas éstas, como carentes de conocimientos, experiencias, intereses o expectativas sobre el territorio. La guía responde a una lógica expositiva de libro de texto, que con base en sesiones (talleres temáticos), presuntamente orientadas por un dinamizador que, apoyado a su vez en La Guía para formación en Gestión del Riesgo (Unidad Nacional de Gestión del Riesgo de Desastres, 2013b), desarrolla los diferentes temas desde una lógica lineal, sin incorporar espacios y mecanismos que den cabida a las distintas formas de ser, pensar y expresar el territorio, sin duda, factores generadores tanto de vulnerabilidades como de competencias sociales. Además, la guía, pensada para comunidades que tengan habilidades lecto-escritoras desarrolladas, limita su acceso y aplicabilidad en comunidades rurales apartadas, demasiadas en Colombia, por el tipo de lenguaje ambiguo (técnico-popular) y la necesidad de tener talleristas especializados que orienten los procesos de análisis y clasificación de la información. Es de notar también que, si bien la guía se basa en las tres etapas del riesgo definidas en la Ley 1523/12, conocimiento del riesgo, reducción del riesgo y manejo de desastres, en ningún apartado se habla de manera explícita sobre la comunicación del riesgo, su sentido, alcances y mecanismos.

Un segundo elemento de gran relevancia para nosotros es que la Comunicación del Riesgo debe propiciar no sólo mayores niveles de consciencia social y política sobre los riesgos, sino una mayor simetría en la distribución global del riesgo ¿Pero es esto último posible? nos preguntamos ¿ldeas y supuestos pueden modificar la realidad en que vivimos? Si reconocemos la génesis y el carácter social y político de los riesgos, en tanto interacción naturaleza-sociedad, al sensibilizar 
y generar consciencia en el sector público y privado sobre los factores genuinos de vulnerabilidad, y en la sociedad sobre el comportamiento espacial de ello, entonces es de esperar que aquellas comunidades y sociedades más expuestas demanden con mayor exigencia a los agentes del poder económico y político, no sólo un mayor nivel de información sobre sus acciones, sino una coherencia entre los costos generados por éstas y los beneficios reportados localmente, propiciando así una redistribución de los agentes generadores de vulnerabilidad y con ello del riesgo.

Y es que las singularidades del mundo contemporáneo han generado una presencia casi indeleble del riesgo como su sello particular (Beck, 2008; Luhmann, 2006): deterioro ambiental, aplicación militar y civil de energía nuclear, uso desbordado de químicos y artificiales en alimentos procesados, armas químicas y neurológicas, manipulación genética de cultivos, ocupación generalizada de áreas inundables y de zonas de laderas y sísmicas, exclusión, segregación y marginalidad urbana, etc., etc. Varios de éstos, tal vez la mayoría, participan en la configuración de riesgos silenciosos, no percibidos ni asumidos, pero reales, globales y sistémicos; no importa dónde se esté o qué se haga, si se está sobre la superficie del planeta automáticamente se está expuesto y en cierta condición de vulnerabilidad, sin saberlo si quiera, a alguno o algunos de ellos. Por ello no se trata de informar a las comunidades sobre los riesgos a los que están expuestas sino de fortalecer la relación entre episteme, percepción, consciencia, ética (deontología) y gestión del riesgo, para producir procesos comunicativos que propicien la construcción de supuestos y acciones más acordes con condiciones de mayor seguridad de los individuos y las sociedades; en esa medida, es claro que la comunicación es un instrumento de poder al servicio de quien la maneja, si sus expresiones, relaciones e intenciones se hacen más transparentes se resquebrajará la hegemonía y el poder de quien la controla y emergerán mayores demandas sociales de equidad a la información, de acceso a los recursos satisfactores, como condición de fortaleza ante amenazas y riesgos, y de responsabilidad política y empresarial ante los agentes y factores generadores de vulnerabilidad.

Pero entonces ¿Qué implica la comunicación del riesgo? Seguimos preguntándonos. Pues bien, para nosotros, la comunicación del riesgo se trata de un complejo proceso de reconocimiento, visibilización y configuración, de conceptos, intenciones, percepciones, reglas e incluso situaciones, en las que se construye pensamiento y acción sobre el riesgo y sus componentes y el significado e impacto social y político que adquiere su descodificación. Es claro que "la comunicación hace visible (o invisible) el riesgo, sirve para poner en común las diferentes definiciones y hacer públicas las políticas y las decisiones tomadas. Más aún, las comunidades de riesgo han de poner el acento en comunicar sus intenciones, en explicarse para justificar sus acciones, y en intentar acercar la visión del resto de actores a la suya sobre la definición del riesgo, su aceptación y las medidas de control a adoptar. La comunicación como eje vertebrador puede ser clave a la hora de entender los procesos de circulación de los discursos de las diferentes comunidades de riesgo" (Gonzalo \& Farré, 2011, p.68).

Böholm \& Corvellec (2010) al referirse a la teoría del riesgo, expresan que el riesgo es una creación semántica que ocurre en el contexto de la comunicación y que la comunicación eficaz del riesgo depende de la comprensión de la dinámica de los objetos en riesgo, las relaciones del riesgo y los objetos en riesgo. Con ello, dejan entrever que la comunicación no puede ser escindida de la visibilización del riesgo, su percepción social, de las redes que se tejen alrededor de él, de la gestión de la confianza, como hecho institucional y social, y de la regulación que se produzca, como producto de todas las anteriores.

Por ende, la comunicación del riesgo más que herramienta al servicio de la información del Establecimiento debe permitir construir espacios, mecanismos e instrumentos permanentes de interacción y retroalimentación, tanto, entre los distintos niveles de la realidad que establece la sociedad del riesgo, como de la gestión social de éste y por ello, no puede considerarse ni independiente, ni externa, ni únicamente producto final, de salida, del proceso instrumental de la gestión del riesgo. Ésta debe contemplar las esferas política, técnica y social, como fuentes poderosas en los procesos de definición, significación y gestión del riesgo. Desde lo político, la decisión sobre qué se comunica, quién lo comunica y cuando se comunica, trata de conservar "la unidad" en la información que se divulga y a través de ello mantener el control de ésta y de la situación misma. Desde lo técnico, la teoría del riesgo construye los paradigmas que definen respuestas y preguntas válidas 
para la comunidad científica y que como conocimiento-poder codifica el marco jurídico y operativo de los niveles locales; empero, no hay que olvidar que el riesgo de la sociedad global está repleto de secretos, incertidumbres y falacias, que expresan intereses económicos y políticos particulares y que contradictoriamente al buscar minimizarse la percepción del riesgo, ocultando información, no se hace más que incrementarlo. Desde lo social, la comunicación del riesgo debe incidir en una mayor percepción del riesgo y en propiciar la construcción de consciencia y ética del riesgo.

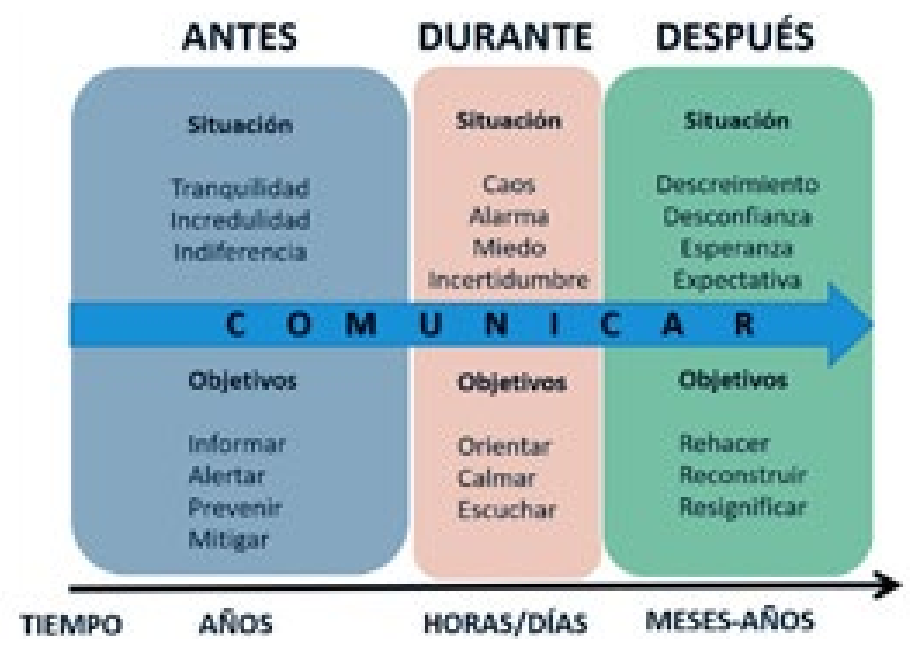

Figura l: Objetivos de la comunicación del riesgo según los momentos de gestión Fuente: Autores, 2018

Igualmente, es importante tener presente objetivos-acciones de la comunicación del riesgo en función de los momentos y tiempos de su gestión. La figura 1 sintetiza ello, allí se aprecia que la comunicación es permanente pero diferenciada según objetivos y alcances de las actuaciones en cada uno de los momentos. En el antes se debe mantener la atención de todos los sectores alrededor de las acciones de prevenir y mitigar, como condición inherente a la gestión. En el durante, como situación de crisis, se busca que la comunicación logre el objetivo fundamental de calmar la población, reducir sus impactos emocionales y sociales, apoyar las actividades de los cuerpos de socorro y favorecer el mantenimiento de la cohesión social en la incertidumbre; por tanto se debe buscar informar clara y permanentemente a la población, definir responsabilidades según protocolos, escuchar sus necesidades y demandas y estar dispuesto a apoyar las labores que requieran los cuerpos especializados. En el después, la comunicación debe potenciar los procesos de resiliencia social y ajuste económico que se necesiten, rehabilitar y reconstruir la materialidad y rehacer y resignificar lo intangible, son los objetivos centrales de este momento. Como se aprecia entonces, la comunicación del riesgo debe estar presente en todos los momentos de la gestión y no sólo en la situación de desastre (como ha ocurrido tradicionalmente en el sector) o de emergencia (como ocurre en el sector salud).

De otra parte, dada la fuerte correlación existente entre la comunicación del riesgo y la percepción del riesgo, un elemento importante para valorar es aquello que se ha denominado como los sesgos en la percepción del riesgo (Martínez, s.f.; Perlof, 1987; Sandman, 2003), por cuanto éstos exigen objetivos y estrategias comunicativas diferentes. El sesgo optimista, aquel que minimiza el riesgo, requiere que la comunicación hacía el público informe, explique y concientice; en una palabra, alerte sobre la probabilidad de ocurrencia y de daño que un evento destructivo podría generar; es decir, aumentar su percepción. El sesgo pesimista, aquel que maximiza el riesgo, demanda que la comunicación entre el sector técnico y la comunidad esté basada en acciones como calmar, escuchar, explicar, analizar y reconocer errores del proceso; en otras palabras, manejar la ofensa. Sesgo optimista o pesimista que se pueden presentar en cualquiera de los momentos de la gestión y que al estar vinculados con condiciones culturales (Douglas \& Wildavsky, 1983) y socio-económicas (Thomas, 2008), y con la ilusión (percepción) de la invulnerabilidad del sujeto y el control de la situación, (Sjöberg et. al., 2004) inciden, intuitiva o racionalmente, a través de un análisis costo-beneficio, en la decisión que el sujeto tome a favor o en contra de asumir un riesgo (Salvador-Ginez, et. al., 2016; Slovic, 1992; Baker, et. al., 2001). 
No obstante, el conocimiento basado en percepciones individuales del riesgo no puede traducirse lineal y mecánicamente en políticas públicas para la gestión del riesgo; si las percepciones se basan parcialmente en sesgos, deformaciones o ignorancias, no parece prudente usarlas así, sin filtro alguno, como decisores para la reducción del riesgo. Además, si las percepciones de riesgo varían entre individuos y grupos ¿Cuáles son las percepciones que deben usarse para tomar decisiones sobre el riesgo y cuáles no? (Renn \& Rohrmann 2000). Empero, estas percepciones si reflejan en muy buena medida las preocupaciones reales, no necesariamente objetivas, de la gente e incluyen los efectos indeseables que los análisis "técnicos" de riesgo a menudo pierden o niegan. Por ello este último nivel, el de la teoría del riesgo, recogido en las visiones del mundo y las disciplinas y las condiciones sociales, políticas, culturales e institucionales de las sociedades que tenemos, da luces para estos cuestionamientos; es desde allí que apreciaciones y valoraciones individuales, que pasan por discusiones y validaciones académicas y científicas y por significaciones culturales, políticas y normativas, se tornan colectivas y posibilitan, a modo de hipótesis, formular políticas para la gestión del riesgo. La comunicación de éste, por su parte, juega papel preponderante en la estructuración de los paradigmas científicos de ella, de la construcción de condiciones sociales que den valor, significado y significancia a éstos y, como ya se planteó, posibiliten mayor equidad en la distribución social del riesgo y de las capacidades para la gestión.

Otro factor importante es la articulación entre los niveles de construcción y actuación del riesgo desde la escala global a la local y viceversa (Figura 2), que definen fuertes tensiones y roles de poder diferenciados. Desde el ámbito global, en el marco de la teoría del riesgo, factores económicos, políticos y culturales, incluida por supuesto la sociedad del conocimiento, definen no sólo una emergencia sistémica y universal del riesgo, sino las concepciones de éste; éstos inciden a su vez en las escalas locales, tanto en la definición de políticas e instituciones que buscan reducirlo, como en la formulación de estrategias de adaptación. Así mismo, margen de maniobra y percepción se hacen más difusos a medida que nos vamos distanciando de lo local, precisamente por la condición indefinida, imprecisa y deslocalizada de éste, produciendo fuertes dependencias y conflictos estructurales de difícil solución en la escala local. Se presenta entonces, una distancia entre la elaboración global de políticas y sus impactos locales, que inciden en las posibilidades de actuación y percepción de los actores.

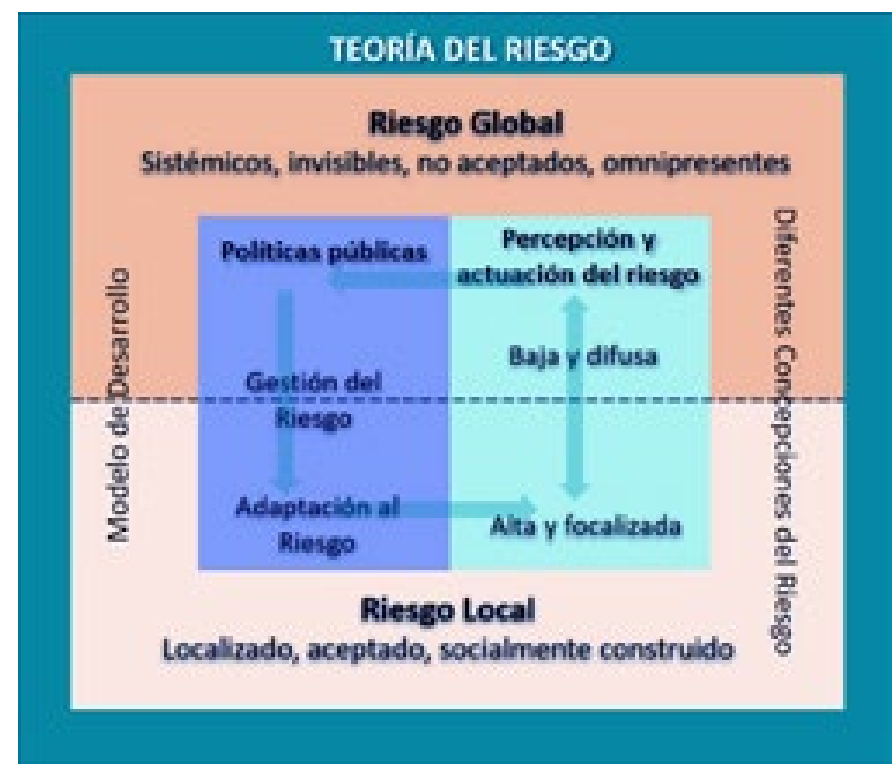

Figura 2: Interacciones entre el riesgo global y local Fuente: Autores, 2018 
Un riesgo claramente percibido impele como mecanismo de protección una serie de respuestas calculadas que reduzcan el nivel de daño, que el individuo no está dispuesto a asumir, en su eventual ocurrencia. A medida que la percepción se hace más consciente, el nivel de tolerancia se reduce, el cálculo de pérdida se agudiza y su aceptabilidad como un hecho inherente a su ocurrencia también disminuye. Por tanto, este es un elemento que debe valorarse en su justa medida en los procesos de gestión del riesgo.

Por ello, la comunicación del riesgo juega papel preponderante en la Gestión del Riesgo; ésta construye conceptos, realidades y posibilidades de actuación, en los distintos niveles en que opera la realidad (desde lo global a lo local y viceversa), y además debe permitir la puesta en común de las instituciones, los expertos y el público en general, alrededor de las diversas situaciones que se den, definiendo canales de múltiples entradas que permitan una construcción dialógica que minimice los sesgos por control de la información. Esto exige de los expertos en el tema de la comunicación, inmensos niveles de responsabilidad social frente a qué, cómo y cuándo se informa, más allá de los intereses de rating que los puedan movilizar.

En esa medida la comunicación del riesgo debe asumirse como un pilar en la construcción de una gobernanza del riesgo, en los que los principios de transparencia y rendición de cuentas trascienda la política pública y se incorporen en exigencias a empresas multinacionales y a agentes generadores de riesgo y en la que los canales de comunicación sean su medio de difusión y control social. Por tanto, la comunicación del riesgo para la gobernanza de éste debe permitir, a través de su actuación, reducir los niveles de incertidumbre, propiciar un aumento de la participación en la toma de decisiones, potenciar procesos eficientes y racionales de autorregulación y ser agente de procesos democráticos. Como se ve, no se trata simplemente de informar sobre alarmas tempranas, procesos de reubicación o restricciones de ocupación y uso del suelo.

\section{EL TALLER COMO ESTRATEGIA PEDAGÓGICA PARA LA GESTIÓN Y COMUNICACIÓN DEL RIESGO}

La comunicación del riesgo, por su naturaleza y alcances institucionales, sociales y comunitarios, exige una estrategia pedagógica que potencie el trabajo en equipo, el desarrollo de la creatividad, la construcción y apropiación de constructos, la recreación y significación de experiencias previas de los sujetos y la valoración de lo cotidiano, como posibilidad de aprendizaje; ello permitirá que la comunicación no se entienda, equívocamente, como información, sino como proceso activo, abier to y en permanente construcción. Precisamente, el Taller posibilita todo ello, éste permite, en el caso particular de la gestión del riesgo, contextualizar y resignificar el conocimiento cotidiano para la identificación de situaciones de amenazas, vulnerabilidades y riesgos, como las potencialidades y capacidades, individuales y colectivas, para la gestión de éste, así como, descubrir y dimensionar los diferentes niveles de responsabilidad y co-responsabilidad que los diversos actores tienen en unas y otras: todo esto, en un entorno pedagógico co-creativo, co-laborativo y lúdico, que propicia un aprendizaje significativo.

El taller permite poner sobre una balanza la creatividad y el método, el pensamiento y la acción, lo individual y lo colectivo, la experiencia y la vitalidad, enriqueciendo la construcción de saberes, que desde distintos focos entran en interacción, generando contextualizaciones de los conocimientos previos o cotidianos y lenguajes renovados. A través de éste se descubren novedades en lo cotidiano, se adquieren nuevos juicios, se elaboran y contrastan raciocinios, se descubren y desarrollan destrezas y se construyen respuestas a los problemas viejos o a los recientemente descubiertos a través de la interacción con otros.

La dinámica del mundo contemporáneo y la emergencia cada vez más rápida, compleja y generalizada de amenazas y riesgos, obliga a que los saberes construidos localmente se constituyan en un producto social, insumo para el conocimiento y comprensión del territorio y para la gestión del riesgo. En ese sentido se necesita que la teoría y la práctica puedan interrelacionarse en los momentos de construcción participativa de los planes comunitarios de gestión del riesgo.

Retomando los trabajos de Thomas \& Muñoz (2012), Egg (1999) y Maya (2007), proponemos una serie de principios pedagógicos del taller, que lo validan como estrategia pedagógica para la comunicación del riesgo: 
- Democratiza las relaciones pedagógicas. A pesar de haber un "maestro" el aprendizaje no se centra en él, como tampoco en los "aprendices", sino en las relaciones establecidas entre todos sus integrantes, siendo tan importantes los resultados como los procesos involucrados. La permanente interacción entre los participantes posibilita la emergencia de procesos deconstructivos y reconstructivos de conceptos y procesos mismos. Esto impele entre todos sus integrantes, más allá de sus roles particulares, relaciones horizontales y establece unas condiciones favorables para el intercambio de experiencias y saberes. Reconociendo las especificidades de cada uno de ellos el taller permite la construcción de simetrías comunicativas, cognitivas, experienciales y personales.

- Unifica la teoría y la práctica. La construcción de saberes va de la teoría a la práctica y viceversa, como vías complementarias de un mismo proceso; el primer camino define referentes teóricos y metodológicos que fundamentan los procedimientos y le dan validez a los resultados y la vía, práctica-teoría, convalida esta última en su capacidad de dar respuesta a situaciones reales y particulares, así como, potencialmente, de formular nuevos postulados a partir del análisis de los resultados hallados en la práctica. El taller puede tomar como punto de partida cualquiera de las dos vías y los resultados, aunque adjetivamente distintos, serán sustantivamente iguales, dado que el taller incorpora de forma integral teoría y práctica; la diferencia radica en la puesta didáctica en particular. Lo cierto es que teoría y práctica, allí se comportan como complementarios, que facultan la construcción de situaciones reales que incorporen fundamentos teóricos, y de reflexiones que tengan principios de realidad claros, plausibles y con significado social y contextual.

- Propicia la creatividad. La metodología del taller posibilita la implementación de diversas estrategias y recursos pedagógicos y didácticos que, centrados en el constructivismo, recogen las experiencias y saberes previos de sus participantes. Igualmente, como quiera que las situaciones "construidas" son múltiples y diversas, se potencian las propuestas y soluciones creativas y no meramente instrumentales. La construcción continua de preguntas lleva concomitantemente la búsqueda permanente de respuestas, unas y otras están tanto en los sujetos participantes como en las interacciones del colectivo que, en un espacio eufórico, pone en permanente juego la creatividad y la originalidad, como parte esencial en la construcción de nuevas asociaciones de pensamiento y de acción, de confrontación de situaciones y en la solución original de problemas.

- Desarrolla la autonomía y el liderazgo. El desarrollo de los talleres propicia el liderazgo y la autonomía, sin desmedro de la participación y la construcción colectiva. La orientación de un experto es el punto de partida en la formulación de objetivos y recursos propios en la identificación de problemas del entorno inmediato, así como de sus alternativas de solución, pero éste actúa como facilitador de los procesos comunicativos, sensoriales, cognitivos o motrices y no como punto de partida y llegada del proceso. El trabajo individual, autónomo y creativo, se complementa y resignifica con y en el colectivo. El liderazgo emerge no como imposición en la organización jerárquica de tareas, sino como fruto de la interacción colectiva y en el reconocimiento social de capacidades y potencialidades individuales.

- Recupera la cotidianidad. El taller incorpora preconceptos, conceptos y experiencias vividas, en igualdad de importancia, pero con diferente significancia, condiciones y alcances. Unos y otros dan razón de la cotidianidad como condición de la realidad. Cultura, Sociedad, Naturaleza y Conocimiento, se entrecruzan para interpretar situaciones y circunstancias y configurar respuestas tentativas a las condiciones dinámicas del entorno inmediato y del mundo referente. Lo vivido por el sujeto en su experiencia cotidiana se convierte, en el desarrollo del taller, en conocimiento con sentido y significancia; las vivencias cotidianas, cognitivas, motrices, sociales y culturales, inciden de forma superlativa en la construcción de visiones e interpretaciones de la realidad y son la materia prima para la elaboración de situaciones de trabajo conjunto en el taller.

- Se aprende en contexto. La contextualización y significación del conocimiento favorece su apropiación e interiorización; ello deviene en habilidades y competencias para observar, conceptuar y proponer. Sin embargo, su objetivo final no es dar resultados acabados, monolíticos o verdades absolutas, debe permitir dejar abiertas posibilidades de hacer, a partir de nuevas 
situaciones e instrumentos dados. El aprender a aprender adquiere mayor relevancia en el taller pedagógico, que el aprender haciendo del taller artesanal; se pretende básicamente que situaciones pedagógicas y construcciones teóricas deriven en el hacer pensando y en el pensar haciendo, par que materializa las necesidades de las comunidades contemporáneas, en especial cuando se trata de gestión del riesgo.

- Da significado social al conocimiento. Más importante que el conocimiento individual, aislado, el mío, es el producido colectivamente, el nuestro, aquel que al margen de roles o eventuales jerarquías surge de la puesta en común. Nociones y conceptos se ponen al servicio del colectivo y adquieren significado y significancia al contrastarse con las realidades, necesidades y expectativas de los grupos y en su capacidad misma de resolver sus problemas. El conocimiento que se construye antes que poder, como instrumento de legitimación institucional y control social, es saber actuante y coherente de las comunidades, en sus contextos particulares; es un conocimiento emancipatorio al posibilitar romper el tradicional esquema paternalista que define la relación entre el Estado Central y las comunidades marginales, las más expuestas a situaciones de riesgos.

- Potencia el pensamiento heurístico. Las actividades desarrolladas en el marco del taller deben estar enfocadas en situaciones concretas de las comunidades participantes y en buscar y construir alternativas de solución a sus problemas. La presentación y significación de experiencias, el desarrollo de habilidades y competencias y la construcción de conceptos y saberes, se ponen de forma coherente y sistemática al servicio de la "invención" de posibilidades de intervención y resolución de sus problemas, limitaciones y conflictos. Se trasciende paulatinamente de la experiencia individual a la colectiva, para construir medios, principios, reglas y estrategias, que propicien la solución más eficaz y pertinente al problema que se confronta colectivamente.

- Desarrolla la integralidad del sujeto y del conocimiento. La naturaleza del taller implica en su desarrollo, actividades cognitivas, motrices y psicosociales. Todos estos son campos de crecimiento del sujeto y todos, en mayor o menor medida, según cada individuo, intervienen no sólo en su crecimiento intelectual, emocional y social, sino en la forma como este construye el conocimiento. Es por ello que el taller permite que sus participantes vivan el aprendizaje como seres íntegros y no solamente abordando lo cognitivo, ya que además de conceptos, se manifiestan y desarrollan habilidades, se dan a conocer experiencias de vida y se confrontan y comparten emociones, estrechando así las relaciones entre lo intelectual, emocional, motriz y psicosocial, dando como resultado una formación integral del individuo, sin menoscabo alguno de ninguno de los componentes que definen la esencia de su ser.

Metodológicamente, los talleres pedagógicos requieren tener una estructura que defina claramente la interrelación entre objetivos, fases, actividades, intenciones, tiempos y ritmos. Se trabajó con una estructura que incorporó fases o momentos que hicieron operativos, a través de objetivos específicos, el sentido general (objetivo) del taller (Figura 3). Cada una de estas fases contó también con una serie de actividades que incluyeron labores motrices, cognitivas y/o psicosociales, con intencionalidades determinadas, que demandaron cierta intensidad para garantizar la focalización de la atención y las expectativas de los asistentes en el taller. Intensidades y duraciones unidas entre sí, establecieron el ritmo general del taller, entendido éste como la simetría y armonía del movimiento (las actividades) que estableció la dinámica del taller en su conjunto.

La Figura 3 ilustra esta situación, allí se aprecia gráficamente, que aquello que llamamos fases están concatenadas entre sí y las actividades están supeditadas a un objetivo específico o particular; es decir, el desarrollo de actividades en el taller no debe entenderse como un activismo; hacer por hacer o mantener a los asistentes ocupados o activos per-se; éstas realmente son un medio para alcanzar los objetivos propuestos. Por su parte, la intención es la concreción de un acto determinado que se lleva a cabo en pos de lograr el objetivo específico, a través de la(s) actividad(es) implementada(s); por ejemplo, un objetivo específico del taller fue confrontar a los asistentes a una situación de riesgo y las actividades desarrolladas fueron: i) sensibilización, ii) salva tu vida y iii) el desinformador, cada una de ellas establece con cierta lógica y coherencia unos pasos para 
recrear y vivenciar colectivamente una situación potencial de riesgos. Allí cada actividad se formula con una intención específica, que en el caso propuesto, fue, respectivamente: i) sensibilizar a los asistentes, ii) tomar decisiones en situaciones de crisis y en estado de vulnerabilidad y iii) confrontar con el auditorio el papel de los medios de información y reflexionar sobre su accionar en situaciones de crisis.

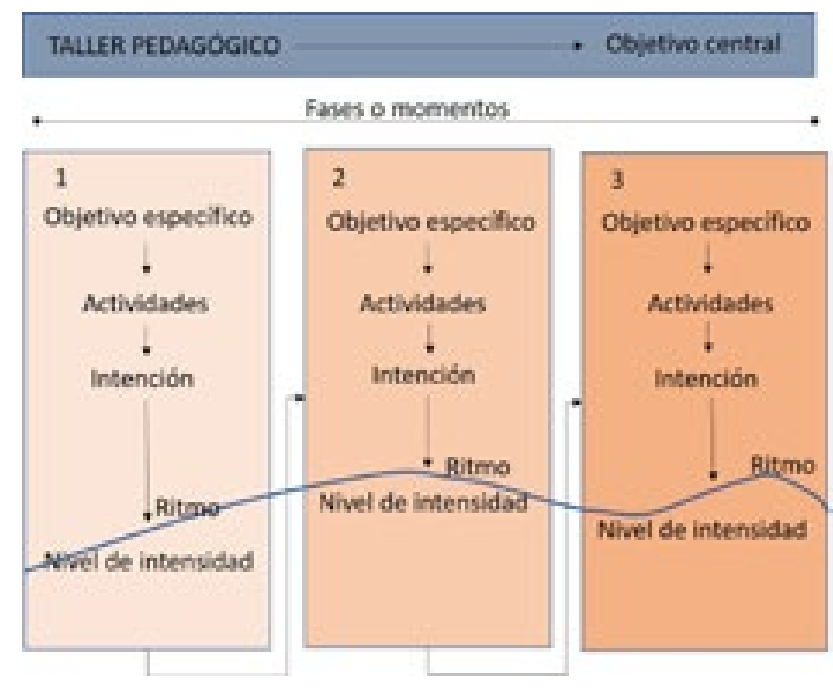

Figura 3: Estructura de los talleres pedagógicos Fuente: Autores, 2018

Un elemento que es importante tener presente en el diseño del taller, para definir unas condiciones que mantengan la atención focalizada y un equilibrio entre la tensión permanente y la relajación total y entre las labores físicas, cognitivas y psicosociales desarrolladas, es el ritmo de éste, definido como ya se expresó, por la secuencia de las intensidades de las distintas actividades; para ello, se propone una matriz que muestra las valoraciones de las intensidades de las labores a desarrollar; el ideal es que la intensidad de las distintas labores esté siempre alta, pero esta condición es bastante difícil de mantener de forma permanente durante todo el taller; entonces, se debería procurar que, en ningún caso, cualquiera de ellas caiga al nivel bajo de intensidad (Tabla 1) Igualmente, es importante tener presente que la cantidad de temas desarrollados en el taller no es un indicador válido para evaluar su pertinencia y eficacia, se trata es de la capacidad de asimilación, interiorización y apropiación de las situaciones construidas en él.

\begin{tabular}{|c|c|c|l|}
\hline VALORACIÓN & $\begin{array}{c}\text { ACTIVIDAD } \\
\text { FísICA }\end{array}$ & $\begin{array}{c}\text { ACTIVIDAD } \\
\text { COGNITIVA }\end{array}$ & $\begin{array}{c}\text { ACTIVIDAD } \\
\text { PSICOSOCIAL }\end{array}$ \\
\hline \multirow{2}{*}{ 3. ALTA } & $\begin{array}{c}\text { Requiere de } \\
\text { bastante } \\
\text { movimiento } \\
\text { corporal }\end{array}$ & $\begin{array}{c}\text { Será necesario re- } \\
\text { conceptualizar en contexto }\end{array}$ & $\begin{array}{l}\text { Se debe mostrar aptitud de liderazgo, } \\
\text { mostrando y poniendo al servicio del } \\
\text { colectivo, habilidades y destrezas } \\
\text { propias }\end{array}$ \\
& $\begin{array}{c}\text { Requiere de algún } \\
\text { movimiento } \\
\text { 2. MEDIA }\end{array}$ & $\begin{array}{c}\text { Se reflexiona sobre } \\
\text { algunos conceptos } \\
\text { abordados en otras }\end{array}$ & $\begin{array}{l}\text { Se participa activamente en algunas } \\
\text { actividades, y/o esperar a que le } \\
\text { indiquen que hacer }\end{array}$ \\
\hline \multirow{2}{*}{ 1. BAJA } & $\begin{array}{c}\text { No requiere de } \\
\text { movimiento } \\
\text { corporal alguno. }\end{array}$ & $\begin{array}{c}\text { Hay poca o nula reflexión } \\
\text { sobre el tema de } \\
\text { convocatoria }\end{array}$ & $\begin{array}{l}\text { Su participación en las diferentes } \\
\text { actividades se limita a observar y en } \\
\text { pocos casos a hacer lo que le designe. }\end{array}$ \\
\hline
\end{tabular}

Tabla 1: Valores de intensidades para las actividades del Taller Fuente: Autores, 2018 
En síntesis, la fortaleza del taller como estrategia pedagógica para la comunicación del riesgo está dada; primero, en su capacidad para construir escenarios de trabajo intelectual, psicosocial y motriz, que potencia los procesos de enseñanza; segundo, por el aprendizaje significativo, participativo e integral de sus participantes; tercero, su contextualización en los escenarios locales; y finalmente, su eventual multiplicación, como posibilidad futura de aprendizaje.

\section{EL FANZINE COMO HERRAMIENTA PARA LA COMUNICACIÓN SOCIAL DEL RIESGO}

Uno de los rasgos de las sociedades contemporáneas es su potencial comunicativo. Como nunca antes, los desarrollos tecnológicos han puesto énfasis en diversidad de dispositivos y tecnologías que producen, circulan y fomentan infinidad de información en tiempo real. Las redes sociales, la web, la televisión veinticuatro horas y la tradicional radio, suponen una sociedad interconectada e informada de los acontecimientos y hechos que se suceden en el mundo; la sensación de estar conectado, a través de dispositivos tecnológicos, tiene como centro la producción de información de muy variada índole que le permite al usuario o ciudadano "estar informado".

En el caso de la comunicación de los riesgos, como componente esencial de la gestión social del riesgo, es interesante reconocer que, en las redes sociales, programas televisivos y en la misma web, aquello que se comunica tiene dos características regulares. De un lado, se presenta información de eventos que se denominan "desastres naturales" que, en muchas ocasiones, sin un contexto de su origen, sus implicaciones y causas, dejan sólo el mensaje de la catástrofe y los daños sociales, económicos y ambientales que ellos traen consigo, incluso, como producto "exclusivo" de la naturaleza, negando el altísimo componente social del desastre. De otro lado, sobre los formatos noticiosos, el privilegio se pone en el saber experto que pretende explicar los motivos de la ocurrencia de los hechos que, por la misma característica del lenguaje técnico y académico, hace que el mensaje no sea comprendido por la mayoría de los ciudadanos. En el caso de las oficinas de gestión del riesgo de los municipios, donde se llevó a cabo la investigación, la información encontrada sobre estrategias para comunicar el riesgo no es mucha, y la existente, es aquella que produce el gobierno nacional sobre el tema, con fuertes rasgos del lenguaje técnico experto, lejano a la realidad y conocimiento de las comunidades locales.

Tanto la información descontextualizada que circula masivamente en redes sociales, como la producida por los expertos, tienen dificultades al no lograr la conexión o pacto comunicativo entre los saberes expertos y contextualizados que existen para dar cuenta de los hechos, y las opiniones, percepciones y saberes que el ciudadano del común elabora sobre los riesgos. Esta distancia cognitiva y comunicativa subyace en la poca comprensión de los posibles riesgos, en las decisiones que toman para poblar un territorio determinado, en la identificación de acciones que mitiguen riesgos y en las posibles alternativas de prevención que cada lugar, comunidad y gobierno local puedan identificar. Es de mucha relevancia, en tal sentido, insistir en el diseño, promoción y difusión de estrategias comunicativas que cierren la brecha entre las administraciones locales y sus oficinas de expertos, con los ciudadanos que habitan el territorio.

Pensar en la comunicación y gestión del riesgo, en el presente artículo, supone reconocer la propuesta de relacionar educación y comunicación, campo de estudio que viene emergiendo en América latina, y tiene como principio axial la relación dialéctica entre comunicación y educación o educación y comunicación, considerando ello, que son asuntos inextricables y por tanto objeto de reflexiones teóricas, metodológicas y ciudadanas. Los orígenes de este campo de estudio se encuentran en los trabajos de Kaplún (1998), Barbero (2002), Huergo (2004), Aparici, et. al. (2010) y para el caso colombiano, la obra de Valderrama (2000).

En este sentido, es importante resaltar el valor que lo comunicativo tiene para la gestión social del riesgo, sin olvidar las otras estrategias de intervención existentes. Por ello es vital, urgente y responsable pensar en Educomunicar el riesgo. Es decir, no se trata de producir mucha información técnica sobre los riesgos, que es importante, sino producir una información que se comunique en clave de educación ciudadana, en tanto la prevención es una acción que debe comprometer al conjunto de la sociedad y de las instituciones encargadas de su gestión, para lo cual se requiere consensuar un lenguaje común que permita comprender los hechos y diseñar alternativas entendibles y viables para el conjunto de ciudadanos. Educomunicar significa hacer uso de la información 
técnica profesional y de aquella producida por la experiencia de habitar el territorio, bajo el principio de construir un conocimiento que, educativamente, fortalezca los lazos interinstitucionales y ciudadanos para la prevención.

Pensar y hacer comunicación del riesgo, parte de animar y promover un diálogo social y de concertación, junto a un espacio para la toma de decisiones frente a los programas y proyectos que existan sobre el tema; esto demanda tener presente, a la vez que potenciar, tres criterios centrales:

- Lo local-territorial que exige y demanda una lectura crítica a los hechos y fenómenos socio-ambientales que se suceden en los territorios, trascendiendo lecturas globales o macros que invisibilizan la realidad social cotidiana y propia de cada sector del municipio. Si bien existen clasificaciones generales sobre los riesgos, lo más importante es contextualizar o situar su presencia en lugares específicos de ocurrencia y así valorar las acciones posibles.

- Valorización de los recursos disponibles en el lugar o territorio particular, expresados en sus dimensiones humana, cultural, social, ambiental y económica, que reconozca que existe un conjunto de potencialidades sociales y comunitarias, las cuales merecen atención y deben ser tenidas en la cuenta para lograr los cambios requeridos. Hacer un mapeo de los recursos existentes ayuda a concretar las acciones y de la misma forma, a identificar aquellos que ameritan conseguirse.

- Reconocimiento del conjunto de potencialidades y capitales sociales que existen y perviven en los sectores, barrios y comunas, expresado en asociaciones, grupos, organizaciones y liderazgos comunitarios que son apoyo y agentes de relaciones entre los diferentes actores institucionales y comunitarios ya existentes. Las organizaciones en su conjunto constituyen un actor vital de los procesos de prevención e implican, de parte de los actores externos, un lenguaje incluyente y proactivo para con los sujetos que habitan y viven en los territorios.

Una estrategia educomunicativa para concientizar sobre los riegos tendría como marco de referencia los criterios y elementos anteriores, subrayando la imperiosa necesidad de que la información que se produzca incida en la vida cotidiana de los ciudadanos y en las dinámicas de trabajo de las instituciones encargadas de la gestión de riesgos. También es importante resaltar que la estrategia comunicativa propuesta no es una camisa de fuerza, por el contrario, ella debe concebirse y entenderse como posibilidad flexible y contextualizada a cada territorio, según sus realidades socio-ambientales, comunitarias e institucionales.

En los talleres realizados se utilizó el fanzine como herramienta que fortalece la estrategia comunicativa para posibilitar ejercicios de educomunicación y ciudadanización sobre los riesgos. La palabra Fanzine proviene de la abreviatura en ingles de Fan's y Magazine, es decir, revista de fanáticos. Lo interesante y sugerente del fanzine es su carácter flexible con relaciones a los cánones y géneros literarios y periodísticos, en tanto en él se pueden combinar y acoplar técnicas que ofrecen distintos géneros. Esto convierte al fanzine en una herramienta comunicativa hibrida y creativa, en tanto le permite a los autores explorar formas alternativas de comunicar, ya que no solo desarrolla lo escrito, sino y de manera importante, lo visual, comprendiendo las fotografías, dibujos, infografías, recortes de prensa etc., además de la creatividad colectiva que se plasma en las texturas, materiales y extensión que se le quiera dar. El fanzine surge entonces, como producción de un diálogo (debate, discusión, negociación) de los actores que, colectivamente, acuerdan qué, cómo, cuándo y dónde comunicar.

Entendiendo lo anterior y reconociendo la flexibilidad enorme de esta herramienta, se subrayan una serie de rasgos o características que orientan la producción del fanzine, no solo en lo técnico, sino en el sentido mismo de su labor y papel comunicativo:

- Una publicación independiente. La intención social de esta herramienta es posibilitar que ciudadanos del común u organizaciones sociales de diferente tipo, puedan producir y circular información que exprese sus puntos de vista sobre temas de interés, que no necesariamente obedecen a versiones o interpretaciones de una institución en particular. 
- Un medio de expresión libre. El legítimo derecho de la libertad de expresión es fundante en el fanzine, en tanto permite que sobre diferentes temas que se suceden en la sociedad, personas del común o grupos al margen del poder, puedan opinar libremente. De ahí la diversidad temas y tipologías a las cuales acude.

- Una revista para aficionados. Una de las ventajas importantes de la producción y uso del fanzine, es el reconocimiento de los saberes cotidianos y del sentido del común como potencialidad para comunicar o informar sobre los hechos sociales. Lo cual no supone el privilegio del conocimiento experto, que es importante porque ofrece una información que se puede usar, pero lo esencial es que los sujetos que lo producen son aficionados, organizaciones sociales o de base, ciudadanos interesados por opinar o comunicar sobre temas de interés.

- Un libro sin límites editoriales. La creatividad y exploración con las formas y/o estilos de la producción de información y su comunicación, hacen del fanzine una herramienta comunicativa que no se encierre en límites o criterios editoriales pre-fijados y definitivos. Lo esencial es comunicar a la mayor cantidad de público posible, de manera clara y ágil, aquello que sus productores reconocen como relevante, enfatizando que es una publicación que trata temáticas no tratadas en los medios masivos de comunicación tradicionales o hegemónicos.

- Una comunicación ágil y viajera. El fanzine debe pensarse en su producción como un formato ágil que garantice, además de su legibilidad, su circulación o viaje sin contratiempos. Es un imperativo que los usuarios o lectores puedan portarlo sin mayor dificultad para su lectura en cualquier momento. Del mismo modo para que lo puedan compartir fácilmente con otras personas y garantizar que el mensaje se expanda.

- Expresión lúdica y didáctica. En su dimensión educativa, esta herramienta, que se produce en un taller de actores o sujetos ciudadanos, institucionales y académicos, debe propiciar el diálogo en un ambiente de respeto y goce del trabajo colectivo, que potencie la producción de la información y su comunicación de tal manera que sea entendible y replicable por el ciudadano o usuario de la herramienta.

Si bien existen una diversidad de posibilidades y opciones de herramientas comunicativas, acercase a la lógica y sentidos del fanzine, ofrece un espacio amplio de experiencias y experimentaciones para la producción y comunicación de las opiniones que gente del común o grupos sociales puedan elaborar. Y es una herramienta para la comunicación del riesgo sugerente, en tanto se nutre de los saberes territoriales específicos y permite la participación de actores diversos.

Para el caso de la comunicación del riesgo esta estrategia resulta de un valor y utilidad social, pedagógica y ciudadana, en tanto permite ser una mediación entre las percepciones, opiniones y/o imaginarios que las personas u organizaciones sociales tienen de su territorio y de los riesgos que en ellos existen, con las concepciones académicas e institucionales que sobre el mismo tema se producen. La perspectiva de educomunicar el riesgo que se sugiere, parte del principio de potenciar el diálogo entre la diversidad de actores o sujetos implicados o relacionados con la gestión social del riesgo, para lo cual el taller como estrategia pedagógica para la comunicación del riesgo, es el escenario de este diálogo

\section{LAS ESTRATEGIAS COMUNICATIVAS PARA LA GESTIÓN DEL RIESGO EN EL VALLE DEL CAUCA}

Los talleres aplicados se estructuraron en cuatro momentos, cada uno con objetivos, acciones e intenciones diferentes pero que en conjunto desarrollaron encuentros con un ritmo sinusal que lograron mantener la participación activa de los asistentes y aumentar el interés conforme el tiempo del taller transcurría.

\section{Primer momento, presentación y reconocimiento del grupo}

Los objetivos de este fueron, introducir a los asistentes en el tema de la comunicación y acercar a cada individuo al grupo para reconocerse y reconocer el espacio en el que se desarrollaba el taller (Figura 4). Se realizaron dos actividades con una fuerte intensidad que buscaba llamar la atención de los asistentes y generar expectativa frente al desarrollo del taller; una puso de relieve 
la importancia de la comunicación y de los canales usados para ella, y dos, el necesario trabajo en equipo que demanda la sociedad contemporánea y la gestión del riesgo. Ninguno de estos dos temas tuvo mayor abordaje teórico, sino que se pretendía dejarlo identificado como producto de las mismas actividades. Ambos hechos se retoman y desarrollan con suficiencia en el tercer momento del taller.

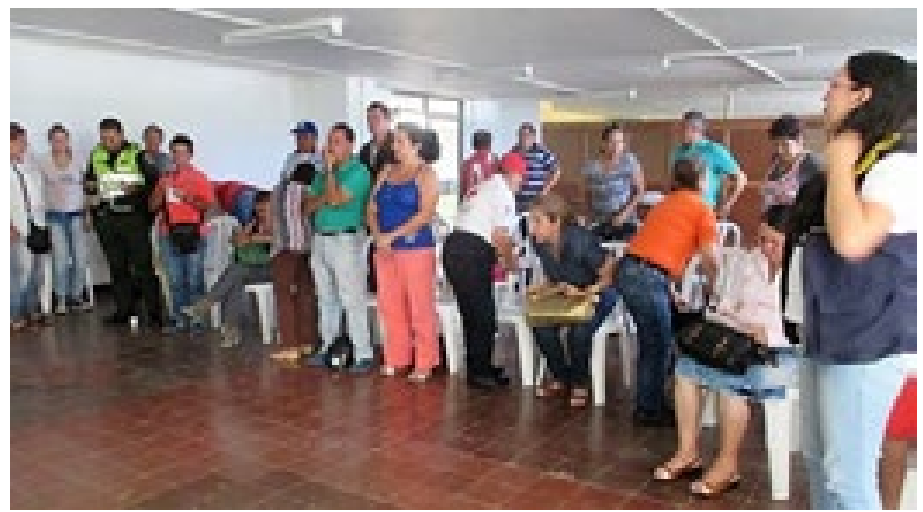

Figura 4: De pie, el grupo de asistentes al taller de Sevilla, presentándose Fuente: Autores, 2018

\section{Segundo momento, construcción de un escenario de riesgo}

Se buscó confrontar a los asistentes a una situación de riesgo y evaluar sus sensaciones y reacciones. Para lograr este objetivo se realizaron cuatro actividades muy relacionadas entre sí. Se partió de recrear las condiciones de riesgo a las que potencialmente han estado expuestos o podrían estarlo, quienes participan en el taller, incluida la oscuridad, asumiendo que el evento ocurría de noche (Figura 5). Precisamente, buscando una mayor conexión con el objetivo del taller, de la situación a recrear y de la naturaleza que define la vulnerabilidad, se les vendaron los ojos a los asistentes y se confrontaron con dos situaciones de emergencia: Un sismo y un incendio, para luego abordarlas de manera cómica, sarcástica y amarillista a través de la teatralización de una reportera que indagó, de una forma muy particular, sobre las experiencias e impactos generados por estos eventos.

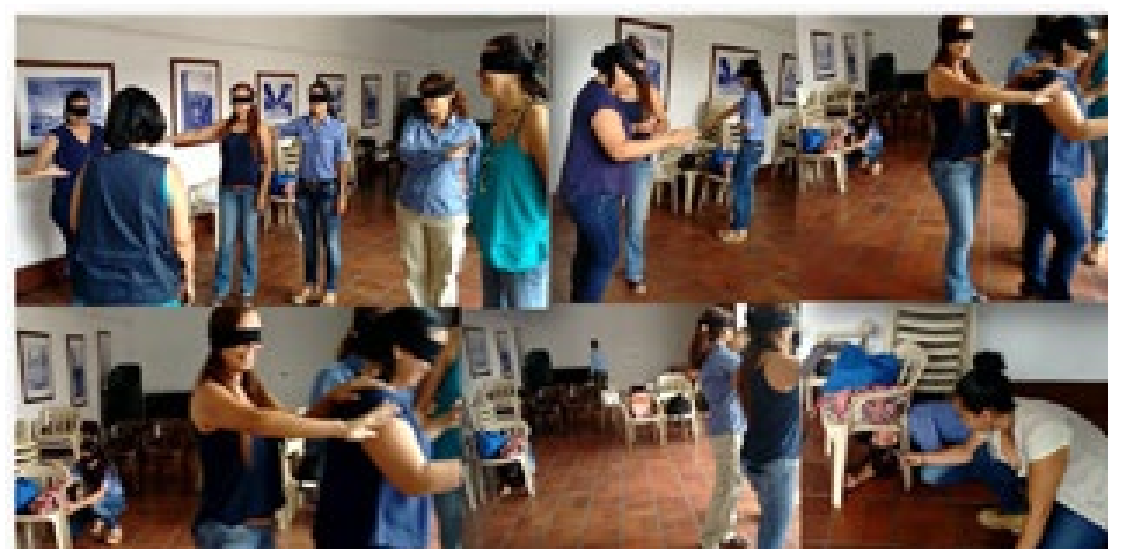

Figura 5: Asistentes al taller de Cali, experimentando el segundo momento, la creación de un escenario de riesgo Fuente: Autores, 2018

\section{Tercer momento, trabajo teórico conceptual}

El objetivo de este momento es construir colectivamente los referentes teóricos fundamentales para la gestión y comunicación del riesgo: Amenaza, vulnerabilidad, riesgo, desastre, gestión del riesgo, comunicación del riesgo y ética del riesgo. Para lograr este propósito se realizaron cuatro actividades. A diferencia de experiencias anteriores o posturas clásicas, no se parte de una exposición magistral de los conceptos de parte del tallerista, sino que se recogieron apreciaciones, 
sensaciones y conocimientos compartidos en la fase anterior, que, junto a las experiencias previas vividas por los asistentes y en un proceso de retroalimentación colectiva, sirven como punto de partida para la construcción de estos conceptos.

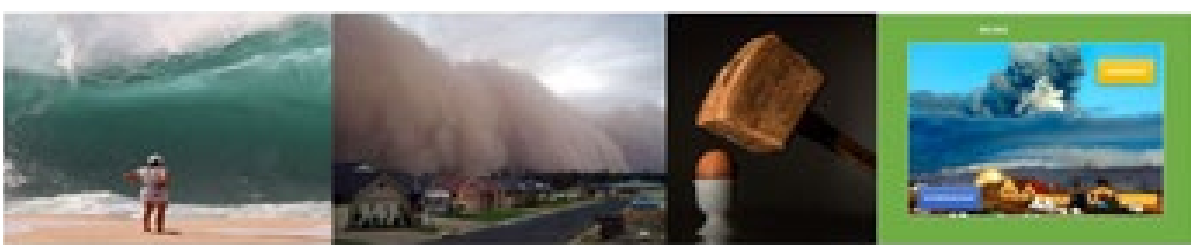

Figura 6: Imágenes utilizadas para la construcción de conceptos claves Fuente: Autores, 2018

\section{Cuarto momento, comunicación del riesgo}

El objetivo específico de este momento es construir una estrategia comunicativa de base social para la comunicación del riego. Se desarrollaron dos actividades. La primera es una exposición muy rápida del origen y manifestaciones del fanzine; luego se resaltaron sus principales características y se propusieron otras más, para el caso específico de la comunicación del riego en comunidades. Para finalizar, los participantes construyeron un fanzine a partir de los elementos discutidos en el taller y los materiales elegidos por ellos de la gama ofrecida por los talleristas.

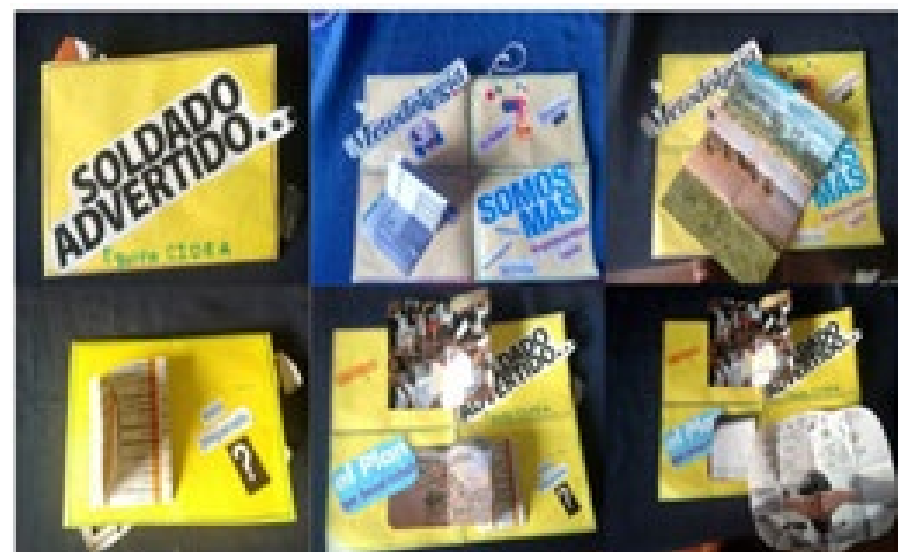

Figura 7: Fanzine construido por un el grupo de trabajo de Cali Fuente: Autores, 2018

\section{RESULTADOS}

La información municipal: planes programáticos, informes técnicos de visitas de campo y atención de eventos, piezas comunicativas, entrevistas a funcionarios y talleres comunitarios; mostraron grandes coincidencias, asociadas a vacíos conceptuales, jurídicos e institucionales, sobre lo que implica la comunicación del riesgo; capacidades institucionales volcadas hacia la atención antes que a la prevención; piezas comunicativas clásicas y tradicionales realizadas por instancias centrales que poco hablan de las circunstancias locales y con lenguajes tecnicistas que dificultan la comprensión de mensajes; recursos financieros y humanos muy limitados para hacer las tareas que demanda la gestión del riesgo, y; manejos políticos en las oficinas que no necesariamente establecen los mejores perfiles para sus cargos directivos. En fin, encontramos que comunicación y gestión del riesgo son reactivos y no proactivos ante las situaciones potenciales de riesgo y que tampoco tienen un lugar político destacado en la definición e implementación de la cosa pública.

Al igual, las condiciones de amenaza y vulnerabilidad de las comunidades siguen incrementándose, municipio por municipio, vereda por vereda. Es decir, mientras las circunstancias institucionales muestran un "Estado de cosas" conflictivo y limitado, con nudos estructurales aparentemente difíciles de resolver de forma inmediata y que requieren voluntades políticas e institucionales fuertes para hacer un cambio, aquellas vinculadas con las condiciones naturales que configuran 
amenazas, y las sociales, económicas, políticas y culturales, que establecen las vulnerabilidades de las comunidades, avanzan a pasos agigantados, generando aparentemente un círculo vicioso que es necesario de alguna manera y en algún momento y punto, romper.

Particularmente en el tema de las estrategias comunicativas para la gestión del riesgo, se pudo constatar que en todos los municipios existen una serie de piezas comunicativas que tratan los temas tradicionales de la prevención: definición, identificación y caracterización de amenazas; presentación de los momentos de la gestión del riesgo (antes, durante y después); definición de vulnerabilidad y esbozos de su caracterización, principalmente; y en algunos otros casos, la gradual incorporación de las nuevas tecnologías de la comunicación (correos digitales y redes sociales).

Empero no se encontraron, de forma significativa, espacios y/o canales de comunicación interactivos que posibiliten una comunicación en doble vía, en el que se pueda incluso discutir sobre saberes, necesidades y prioridades en la información presentada. Inclusive, las piezas generalmente vienen desde Bogotá, donde situaciones, lenguajes y alternativas de solución, descontextualizadas y de bajo impacto comunitario, son la regla. Más aún, no se encontró un nivel de consciencia significativo sobre lo que implica la comunicación del riesgo en sí misma, ni en el proceso de la gestión de éste, más bien, la comunicación se asume como un hecho inherente a la información y que en sí misma no despliega ni genera postulados teóricos, filosóficos o éticos, ni juega papel alguno en la percepción del entorno social e institucional que define los supuestos sobre el riesgo y su distribución social, ni en la identificación y definición de niveles de responsabilidad y corresponsabilidad ante éste.

En cuanto a los talleres, la experiencia tenida en ellos valida integralmente la propuesta formulada. Los principios pedagógicos planteados se evidenciaron en mayor o menor medida en todos y cada uno de los talleres realizados (Tabla 2). Realmente no hubo ninguno de ellos que no fuera demostrado en el ejercicio práctico: los asistentes desarrollaron creatividad y liderazgo, retomaron y resignificaron sus conocimientos previos, le dieron sentido y alcance social a éste a través de la puesta en común y de la construcción colectiva, en un ambiente de camaradería y confianza, analizaron, confrontaron y resolvieron problemas reales y en contexto e hicieron actividades que propiciaron su desarrollo cognitivo, motriz y psicosocial. En fin, el taller como propuesta pedagógica fue validado a través de su práctica, con contundencia y no deja duda alguna.

\begin{tabular}{|c|c|}
\hline Principio & Municipios de Jamundí, Yumbo, Buga, Buenaventura, Sevilla y Ansermanuevo \\
\hline $\begin{array}{l}\text { Democratizador } \\
\text { de relaciones } \\
\text { pedagógicas }\end{array}$ & $\begin{array}{l}\text { En general en todos los municipios, adultos, niños, jóvenes, mayores de edad, } \\
\text { independientemente de su rol y formación, participaron en igualdad de condiciones, sin sentir } \\
\text { que había alguien con mayor formación o poder }\end{array}$ \\
\hline $\begin{array}{l}\text { Unificador de } \\
\text { teoría y práctica }\end{array}$ & $\begin{array}{l}\text { En todos los casos se logró que se articularan los elementos teóricos a las experiencias previas } \\
\text { y preconceptos de los asistentes. Igualmente se crearon fanzines que permitieron demostrar } \\
\text { la facilidad y potencialidad del instrumento comunicativo propuesto }\end{array}$ \\
\hline $\begin{array}{l}\text { Propiciador de } \\
\text { creatividad }\end{array}$ & $\begin{array}{l}\text { La construcción de los fanzines se dio a través de la propia exploración de los materiales } \\
\text { disponibles (cotidianos) y de buscar nuevas y diferentes formas de expresar y comunicar. En } \\
\text { el municipio de Jamundí fue un poco más difícil desprenderse de los esquemas comunicativos } \\
\text { convencionales }\end{array}$ \\
\hline $\begin{array}{l}\text { lador de } \\
\text { úa y }\end{array}$ & $\begin{array}{l}\text { Los asistentes formaron sus propios grupos de trabajo y reconocieron entre ellos mismos } \\
\text { aquellos que podían ejercer mayor liderazgo colaborativo y no competitivo. }\end{array}$ \\
\hline $\begin{array}{l}\text { Recuperador de } \\
\text { cotidianidad }\end{array}$ & $\begin{array}{l}\text { simulación y recreación de eventos extremos (sismo e incendio) partió, evidenció } \\
\text { propias experiencias y les dio valor agregado al discutirlas colectivamente. }\end{array}$ \\
\hline $\begin{array}{l}\text { Aprendizaje en } \\
\text { contexto }\end{array}$ & $\begin{array}{l}\text { El proceso de formación sobre el riesgo y sus agentes se dio no sólo en sus propios municipios, } \\
\text { sino que partió de sus propias realidades locales. En los municipios de Jamundí, Sevilla y } \\
\text { Ansermanuevo, los asistentes en los fanzines realizados abordaron las situaciones locales que } \\
\text { más les preocupaba. }\end{array}$ \\
\hline $\begin{array}{l}\text { Significa } \\
\text { socialmente el } \\
\text { conocimiento }\end{array}$ & $\begin{array}{l}\text { La relación establecida entre todos los asistentes permitió que los contenidos desarrollados en } \\
\text { los talleres, al margen de roles o eventuales liderazgos o jerarquías, se construyera en común, } \\
\text { contextual y significativo para todos. Las instituciones presentes se acercaron al conocimiento } \\
\text { local y las comunidades al científico. }\end{array}$ \\
\hline $\begin{array}{l}\text { Potenciador de } \\
\text { pensamiento } \\
\text { heurístico }\end{array}$ & $\begin{array}{l}\text { La misma construcción del fanzine se constituye en una propuesta de intervención que, dado } \\
\text { la construcción colectiva y el carácter social del conocimiento implícito, tiene alta probabilidad } \\
\text { de acompañamiento social en la implementación de estrategias de solución. No obstante, se } \\
\text { requiere de un acompañamiento y evaluación institucional y social, permanente, para validar } \\
\text { totalmente este principio. }\end{array}$ \\
\hline $\begin{array}{l}\text { Desarrollador de } \\
\text { integralidad del } \\
\text { sujeto y del } \\
\text { conocimiento }\end{array}$ & $\begin{array}{l}\text { Las actividades cognitivas, motrices y psicosociales incorporadas en los talleres, permitieron } \\
\text { el desarrollo de diversas competencias del sujeto y del conocimiento. Se entendió que es } \\
\text { necesario combinar todas para poder producir, integralmente, conocimiento. }\end{array}$ \\
\hline
\end{tabular}

Tabla 2: Evaluación de principios pedagógicos alcanzados en los talleres

Fuente: Autores, 2018 
En relación con la herramienta comunicativa, el fanzine, también se lograron validar sus aportes comunicativos para la gestión del riesgo; su flexibilidad, independencia, autonomía y base social, son garantes para consolidarse como posibilidad real en la comunicación del riesgo municipal. Este, precisamente por su naturaleza; sin reglas establecidas, de bajo costo y absolutamente creativo; ofrece alta capacidad de adaptación a las situaciones presentes en las diversas comunidades y puede replicarse sin problemas, logrando así una alta incidencia social.

\section{CONCLUSIONES}

Un aspecto que vale la pena poner de relieve, es que un Taller Pedagógico no se puede confundir con cualquier tipo de reunión en donde se pone a los asistentes a hacer actividades manuales o donde se suministra información, sin llegar a aplicar los principios planteados y las labores propuestas. De la misma forma, no cualquier persona puede automáticamente convertirse en tallerista, ésta requiere conocimiento de la naturaleza, método y alcances de esta estrategia, como de los aspectos temáticos a barrer en ella.

Otro elemento importante sobre el taller, es que la homogeneidad etaria y cognitiva del auditorio facilita el desarrollo de las actividades a implementar y las estrategias didácticas; no obstante ello, su heterogeneidad no es necesariamente impedimento para su buen desarrollo; la experiencia demostró que más importante que tener un auditorio homogéneo en su nivel de desarrollo cognitivo y en edad, es compartir intereses y expectativas; sin embargo, si se requiere que al diseñar un taller se conozcan las características particulares del público a asistir. En todo caso, es necesario que los talleristas tengan la habilidad de ajustar, en caliente, actividades y alcances del taller si se llega a requerir; es decir, tener siempre bosquejado un Plan B.

Resulta sumamente útil, establecer con antelación el ritmo deseado del taller, para calcular los niveles de esfuerzo, los momentos de descanso y los de clímax a tener, de tal forma que se pueda ejercer mayor control sobre los focos y momentos de atención y dispersión del auditorio.

Sobre la comunicación del riesgo podemos decir que ésta, definitivamente, es un reto de futuro; aún no se entiende, de parte de las autoridades municipales y obviamente de las mismas comunidades, la importancia, alcances y posibilidades de ella. Se debe trascender la percepción mecánica de ésta, la acción de informar a las comunidades de los riesgos a los que está expuesto, donde la responsabilidad es del sector público, quien, en su condición de emisor produce un mensaje, cualquier tipo de mensaje, en cualquier tipo de formato (prácticamente ello no es importante), a las comunidades, quienes, en su calidad de receptores, deben actuar de conformidad con éste, porque se da por sentado que se da la comunicación entre ambos.

La comunicación del riesgo y las estrategias comunicativas para ello, son definitivamente un desafío no sólo para los gestores del riesgo, sino para la academia y las comunidades, porque sin espacios y herramientas que potencien una comunicación interactiva, social y contextual, será muy difícil que procesos graduales de reducción de la vulnerabilidad y seguridad territorial se den de forma masiva y generalizada. Confiamos en que este reto concite la voluntad y los esfuerzos de todos.

\section{REFERENCIAS}

Aparici, R., Crovi, D., Ferrés, J., Gabelas, J., García, M., Gutiérrez, A., Huergo, J., Kaplún, M., Oliveira, de I., Orozco, G., Osuna, S., Prieto, D., Quiroz, M., Scolari, C. \& Valderrama, C. (2010). Educomunicación: más allá del 2.o. Barcelona: Editorial Gedisa.

Baker, F., Dye, J., Denninston, M. \& Ainsworth, S. (2001). Risk Perception and cigar smoking behavior. American Journal of Public Health, 25 (2), 106-114.

Barbero, J. (2002). La educación desde la comunicación. Bogotá: Ed. Norma.

Beck, U. (2008). La sociedad del riesgo mundial: En busca de la seguridad perdida. México, D.F: Paidós, Estado y Sociedad.

Böholm, A, \& Corvellec H. (2010). A relational theory of risk. Journal of Risk Research, Vol. 14, (1-2), 175-190.

Castro, M. Coordinador del Conocimiento del Riesgo de Desastres del Valle Del Cauca. Entrevista personal, realizada el 1 Mayo de 2016 
Congreso de la República de Colombia. Ley 1523 Política Nacional de gestión del Riesgo de Desastres. (2012). Disponible en http://www.alcaldiabogota.gov.co/sisjur/normas/Norma1.jsp?i=47141, Recuperado el 12 de junio de 2016

Douglas, M. \& Wildavsky, A. B. (1983). Risk and Culture: An Essay on the Selection of Technical and Environmental Dangers. Berkeley: University of California Press.

Egg, A. (1999). El taller una alternativa de renovación pedagógica. Rio de la Plata: Editorial Magisterio

Gonzalo, J. \& Farré, J. (2011). Teoría de la comunicación del riesgo. Barcelona: Editorial UOC.

Huergo, J. (2004). Hacia una genealogía de comunicación/educación: rastreo de algunos anclajes políticos-culturales. Río de la Plata, Ediciones de Periodismo y Comunicación.

Kaplún, M. (1998). Una pedagogía de la comunicación. Madrid: Ediciones de la Torre.

Luhmann, N. (2006). Sociología del riesgo, Universidad Iberoamericana. México D.F: Colección teoría social.

Martínez, J. (s.f.). El sesgo optimista y la distancia afectiva en la percepción de riesgo. Revista de Investigación para alumnos de Psicología y Logopedia.

Maya, A. (2007). El taller educativo. Bogotá: Cooperativa Editorial Magisterio.

OPS. (2017). La comunicación de riesgo: preguntas frecuentes. Disponible en http://www.paho.org/ hq/index.php?option=com_content\&view=article\&id=11400\%3Ala-comunicacion-de-riesgo-preguntas-frecuentes\&catid=1625\%3Arisk-outbreak-communication-homepage\&Itemid=41610\&lang=es, Recuperado el 6 de noviembre de 2107

OPS. (2011). Sistematización de Lecciones aprendidas en proyectos COMBI en dengue en la Región de las Américas. San José, Costa Rica: OPS.

Perloff, L. (1987). Social comparison and illusion of invulnerability to negative life events, en C.R. Snyder y C. Ford (Eds.). Coping with negative life events: Clinical and psychological perspectives. Nueva York: Plenum Press.

Renn, O. \& Rohrmann, B. (200o). Cross-Cultural Risk Perception: State and Challenges. Technology, Risk, and Society, Vol. 13, 211-233.

Salvador-Ginez, O., Ortega, P., Rivera, S. \& García, R. (2016). Validez y confiabilidad de la Escala de Percepción de Riesgo de Deslave en la Ciudad de México. Acta de Investigación Psicológica de la UNAM 7, 2618-2626.

Sandman, P. (2003). Four Kinds of Risk Communication, en The Synergist. Journal of the American Industrial Hygiene Association, 26-27.

Sjöberg, L., Moen, B. E. \& Rundmo, T. (2004). Explaining risk perception: An evaluation ofthe psychometric paradigmin risk perception research. Rotunde, 84. Disponible en http://www.svt.ntnu. no/ psy/torbjorn.rundmo/psychometric paradigm.pdf. Recuperado el 6 de noviembre de 2107

Slovic, P. (1992). Perception of Risk: Reflections on the psychometric paradigm, en S.Krimsky y D.Golding (eds.), The Social Theories of Risk. Westport, CO: Praeger.

Thomas, J. \& Muñoz, I. (2012). El taller: Una estrategia pedagógica para la gestión escolar del riesgo. Ponencia presenta en el Congreso de Educación Geográfica 2012, Tunja, Colombia.

Thomas, J. (2008), Armero: Crónica de un desastre anunciado u oda a la negligencia humana. Revista Entorno Geográfico, No. 6.

Unidad Nacional de Gestión del Riesgo de Desastres. (2013a). Guía comunitaria para la gestión del riesgo de desastres, Sistema Nacional Para la Gestión del riesgo de Desastres, Colombia.

Unidad Nacional de Gestión del Riesgo de Desastres. (2013b). Guía para formación comunitaria en gestión del riesgo de desastres, Sistema Nacional Para la Gestión del riesgo de Desastres, Colombia.

Valderrama, C. (200o). Comunicación - Educación. Coordenadas, abordajes y travesías. Bogotá: Universidad Central \& Siglo del Hombre Editores. 